\title{
MONTANI Rodrigo, El mundo de las cosas entre los wichí del Gran Chaco. Un estudio etnolingüístico
}

Zelda Alice Franceschi

\section{OpenEdition}

\section{Journals}

\section{Edición electrónica}

URL: https://journals.openedition.org/jsa/16598

DOI: $10.4000 /$ jsa. 16598

ISSN: $1957-7842$

\section{Editor}

Société des américanistes

\section{Edición impresa}

Fecha de publicación: 15 diciembre 2018

Paginación: 228-235

ISSN: 0037-9174

\section{Referencia electrónica}

Zelda Alice Franceschi, «montani Rodrigo, El mundo de las cosas entre los wichí del Gran Chaco. Un estudio etnolingüístico», Journal de la Société des américanistes [En línea], 104-2 | 2018, Publicado el 15 diciembre 2018, consultado el 02 septiembre 2022. URL: http://journals.openedition.org/jsa/16598 ; DOI: https://doi.org/10.4000/jsa. 16598

Este documento fue generado automáticamente el 2 septiembre 2022.

All rights reserved 


\title{
MONTANI Rodrigo, El mundo de las cosas entre los wichí del Gran Chaco. Un estudio etnolingüístico
}

\author{
Zelda Alice Franceschi
}

\section{REFERENCIA}

MONTANI Rodrigo, El mundo de las cosas entre los wichídel Gran Chaco. Un estudio etnolingüístico, Centro de Investigaciones Históricas y Antropológicas/Instituto Latinoamericano de Misionología/Itinerarios Editorial (Scripta autochtona, 17), Cochabamba, 2017, 607 p., ill. En blanco y negro, fotos en blanco y negro, mapas.

1 El libro de Rodrigo Montani está compuesto por nueve capítulos que recogen su experiencia de campo, iniciada en 2002, en varias comunidades wichí de las provincias argentinas de Formosa (Las Lomitas, Ingeniero Juárez, Teniente Fraga) y Salta (Coronel J. Solá, Los Baldes, Misión Chaqueña), como así también de Bolivia (Villa Montes). Se trata de grupos ocasionalmente horticultores pero dedicados mayormente a la caza, la pesca y la recolección de miel y frutos silvestres: hoy se cuentan en total unos 50.000 wichí distribuidos entre las provincias argentinas de Formosa, Chaco y Salta y de Tarija en Bolivia, donde son llamados 'weenhayek.

2 Con ecos casi lévi-straussianos, la propuesta de trabajo de Montani es ambiciosa, por momentos utópica: describir una sociedad en su totalidad a través de los artefactos, comprender la forma en la que esos artefactos son clasificados dentro de la cultura y, al mismo tiempo, establecer las diversas relaciones posibles entre ellos. Al respecto, hay en el libro varias cuestiones dignas de destacar.

En primer lugar, las circunstancias del trabajo de campo y la metodología. Montani se revela como un etnógrafo impecable que armoniza una evidente predisposición al trabajo cuantitativo con una devoción sincera por la labor cualitativa. Utiliza el Field Linguist's Toolbox para ordenar los datos lingüísticos, las notas de campo, las palabras, las 
frases, los textos libres, las entrevistas parciales o totales; ordena el léxico y los morfemas gramaticales, llegando aproximadamente a los 2.800 términos; estudia la genealogía de unas 1.000 personas; $y$, al mismo tiempo, siempre con delicadeza, comparte algunas páginas de su diario de campo (por ejemplo, la bonita escena de la partida de caza en las p. 309-311). Con paciencia y "buena voluntad", la voz de los testigos es no obstante el criterio definitivo a la hora de aclarar situaciones heterogéneas (la brujería, la menarca, el legado de los difuntos, la construcción del techo de la casa), de traducir los términos significativos, y de familiarizarnos con los conceptos nativos más lejanos a nuestra propia experiencia. Además la etnografía aparece sistemáticamente acompañada por un contraste constructivo con la información que provee la literatura del área (de antropólogos, misioneros, militares, historiadores y lingüistas) y asimismo con una gran cantidad de fuentes museológicas (Museo Etnográfico de Buenos Aires, el Museo Regional de Antropología Juan A. Martinet de Resistencia, el Museo Etnográfico Andrés Barbero de Paraguay, el Museo Histórico Provincial Dr.Julio Marc de Rosario). Esta rigurosa erudición es una de las razones principales de la "densidad" del texto, en el famoso sentido de Clifford Geertz. Se trata, en efecto, de una monografía estratificada en la cual los problemas de interpretación, las elipsis y las incongruencias que invariablemente surgen en el terreno son dilucidadas tanto por el cotejo comparativo como, por sobre todo, por la propia palabra de los interlocutores wichí. El razonamiento argumental siempre resulta explícito y las respuestas del autor dejan abierto el camino a distintas interpretaciones: como los propios wichís, no son pocas las ocasiones en las que, con franca sencillez, el autor comienza su análisis advirtiendo "Hasta donde sé..."

En segundo lugar, el argumento se despliega a partir de una amplia -aunque bien circunscrita- definición de "artefacto". Para Montani un artefacto es la materialización de la acción social en sentido weberiano: un conjunto de atributos cuyas prerrogativas se convierten inevitablemente en el resultado de decisiones técnicas que revelan ciertos condicionamientos sociales, ideológicos y cognitivos. Por lo tanto, no sólo se trata de recorrer la "biografía" de los objetos por medio de un particularismo histórico de matriz boasiana (tal vez el ejemplo más evidente y significativo sea el itinerario social de la bolsa enlazada), sino que se intenta comprender su "agencia" en términos éticos o émicos, y al mismo tiempo en función de su lógica sintagmática y paradigmática (es decir, según sus analogías y relaciones con los medios y fines que entran en juego). Este último punto se desarrolla a fondo en el capítulo octavo, en el cual el análisis lingüístico permite reflexionar sobre la ontología de los artefactos que para los wichís representan entidades intrínsecamente ambiguas. En efecto, estas entidades se encuentran en un espacio liminal desde el punto de vista lingüístico pues algunas de sus denominaciones son nombres dependientes (o inalienables, como suelen decir los lingüistas) y otras en cambio son nombres independientes (o alienables). La pregunta, entonces, es qué conocimiento del mundo puede generar el hecho de que esas denominaciones se adscriban a una u otra categoría: "Por un lado, a diferencia de las entidades autónomas de la 'naturaleza', los artefactos no 'nacen' si alguien de otra especie no los fabrica, no 'viven' si ese alguien no lo usa, y no 'mueren' si ese alguien no los gasta hasta destruirlos; y aunque algunos son tan inalienables como las partes del cuerpo, en su gran mayoría los artefactos pueden ser vendidos, comprados, abandonados, robados -de todos modos, todas estas diferencias son una cuestión de grado y de contextos. Por otro lado, los artefactos se mueven en el espacio complejo que va de la propiedad individual a la propiedad colectiva, del dominio a la posesión y el usufructo [...]" (p.525). Se vuelven particularmente relevantes, así, las numerosas analogías entre las partes del cuerpo y 
algunos artefactos, bien ejemplificadas a través de la imagen -evocadora y en parte naif (p. 523)- que exponen las obras de algunos pintores y pintoras wichís, a quienes se dedica parte del capítulo séptimo. Los artefactos wichís no pueden ser analizados en los términos propios del dualismo filosófico de nuestras sociedades occidentales, pues el wichí es un dualismo relacional: cualquier entidad puede ser intrínsecamente dependiente de cualquier cosa o de alguien y, al mismo tiempo, revelarse como esencialmente autónoma. Así, el estudio clarifica la ambigüedad en la que por lo general han caído las clasificaciones semánticas a priori propuestas por los lingüistas (Hunt, Viñas Urquiza, Terraza, etc.).

5 En tercer lugar, el mito wichí parece acatar un locus clásico de la etnología chaqueña y sigue presentándose como una suerte de "hilo conductor" que permite interpretar, deconstruir o simplemente pensar la sociedad. Una sociedad, por otra parte, cuyos miembros explican por medio de relatos que resultan sorprendentemente potentes por su gran fuerza evocativa y representacional, pero que a la vez escenifican una cotidianeidad inexorablemente frágil. La historia wichí, de hecho, es claramente una transición complicada: degradación ambiental, enfermedades endémicas, malnutrición, pobreza estructural. Pero lo curioso es que el mito sigue ofreciendo una suerte de llave o espina dorsal de la historia. Este punto resulta delicado e intrigante. Si en varias ocasiones se citan o se cuentan mitos, Montani aclara desde el principio que no suele tratarse de historias narradas en primera persona: hay, por ejemplo, un texto que narrando el origen del juego del hockey chaqueño nos conduce hacia una lectura nada trivial de los actuales partidos de fútbol. Otros textos relatan cómo se produjo la apropiación del metal ("El reparto de los bienes en el mundo", "El advenimiento de las mujeres", "La historia del monstruo Kalëchinaj”, "El niño que mató al monstruo Arco Iris", "El niño y el jaguar"), y reflexionan en el proceso sobre el uso actual del dinero. Más previsiblemente, existen otras historias que ilustran la importancia cultural del fuego ("El origen/El robo del fuego") o bien el poder inusual del árbol "palo santo" ("La metamorfosis de Nacurutú"), referidas al tipo de madera que los artesanos prefieren para confeccionar sus tallas: "Es muy dura, su consistencia cerosa evita que se raje al labrarla [...] les gusta porque su veta es vistosa, adquiere más brillo que cualquier otra madera, despide un aroma agradable y no la comen los bichos ni la arruina el paso del tiempo" (p. 471). Y así sucesivamente. En lo que se refiera al mundo de los artefactos, el mito sigue operando como un instrumento fundamental de comprensión. Un dispositivo, pues, pero al mismo tiempo objeto: sabemos que, adquiriendo vida autónoma a través de inesperadas metamorfosis, los artefactos son protagonistas indiscutibles de los mitos. Pero también que los mitos no son una fuente más de conocimiento sino un ejercicio que responde a una precisa voluntad intelectual. ¿Cuál es entonces su papel cuando no son ya objeto privilegiado de performance y se convierten en relatos breves o casi episódicos? El análisis de Montani abre un abanico de posibilidades. Si bien los mitos relatan impecablemente la historia y el significado de los artefactos, ¿podemos afirmar que ilustran las técnicas empleadas en su manufactura, uso o circulación? ¿0 más bien debemos concluir que son los propios artefactos los que se convierten en "metáforas sólidas" de ejercicios mentales refinados y complejos? En otras palabras: ¿son los artefactos el todo de una parte (el mito) que ya no es actuado ni puesto en escena? ¿Y puede develarse la performance del mito a través de la materia in fieri del artefacto?

6 En cuarto lugar, surge el problema de la lengua. Hablada mayoritariamente por los indígenas pero también por misioneros, algunos criollos y unos pocos antropólogos y lingüistas, la lengua wichí (wichi-lhämtes) forma parte de la familia mataco-mataguaya o 
matacoana. Los wichís hablan su lengua adaptándola, incorporando préstamos y evitando las estandarizaciones: quieren escribirla y se demoran traduciéndola de la forma que les resulta más práctica y atractiva (resulta sumamente interesante, al respecto, el reciente libro de Montani junto al autor wichí Gerardo Juárez). Esta vivacidad es bien descripta por el autor a través del análisis de la lengua, que nos propone a su vez varios niveles de lectura del texto. En este sentido prescribe sin imponer (¡tan al modo wichí!) un doble registro de lectura: si por un lado, efectivamente, leyendo el libro desde el comienzo a la conclusión podemos aventurarnos en una etnografía ecléctica pero sabiamente comparativa (Diego Villar en el prólogo), también es cierto que la atención sistemática concedida a la dimensión lingüística lo convierte al mismo tiempo en una auténtica "enciclopedia razonada" (p.534) que puede consultarse provechosamente empleando el índice analítico.

7 Si optamos por la lectura cronológica, los tres primeros capítulos nos introducen casi de puntillas al universo wichí. Lo que es más importante: nos sacan -tal vez de forma definitiva- algunas molestas piedritas de los zapatos al aportar claridad sobre algunos de los temas que a través de las décadas han apuntalado la etnografía wichí. Por ejemplo, "chaqueños", "criollos" y "blancos" son las tres subdivisiones étnicas que se mantienen durante todo el libro: todos ellos son para los wichí süwelëlhais o ahätäylhais (según las regiones). Pero Montani destaca que la actual categoría de "criollo" resulta a la vez demasiado laxa y vaga. Por su labilidad y fragilidad hay algunos espacios que deben ser contextualizados histórica y geográficamente: es justamente la precisión etnográfica la que nos permite comprobar hasta qué punto esas clasificaciones étnicas adoptan modalidades creativas de superposición y distribución en la vida cotidiana.

Pero si pensamos en cambio en el campo del parentesco, podríamos partir de los estudios clásicos de José Braunstein (desde los años setenta) y sobre todo seguir de cerca la etnografía de John Palmer (desde los años noventa hasta hoy) para comprobar que todavía siguen en pie muchos de los términos y reglas de juego. La wichí es, en efecto, una sociedad en la que se buscan los cónyuges potenciales entre aquellas personas clasificadas como afines por los parientes ya casados de Ego: no muy "lejanos", por tanto, pero tampoco excesivamente "cercanos". En todo caso los wichís buscan cónyuges razonablemente distantes como para poner en marcha el principio de afinidad serial que ordena el círculo de los afines reales o potenciales (ihnyäj tä wehnalhamej, "otros diferentes") y de los consanguíneos (ihnyäj, "otros similares"). En este punto resultan particularmente esclarecedoras las páginas dedicadas a los nombres de las parentelas (wichi-lheyis). Montani publica un cuadro de 24 parentelas conocidas por los habitantes de Los Baldes (algunas de ellas no registradas todavía por ningún etnógrafo, como los hoopästey, "picos de gallina" y los kap'ahnalhais, "enanos"). Luego de recoger críticamente los aportes más relevantes sobre el tema (Braunstein, Pérez Diez, Palmer, Barúa, Dasso, Alvarsson), observa que la parentela comienza a operar apenas "concluye" la clasificación genealógica (p. 98), haciendo que en una sociedad bilateral la adscripción a la parentela paterna o materna sea ante todo una cuestión personal, que pone en juego múltiples estrategias políticas, económicas y afectivas (p. 97). Otro punto central ligado con las parentelas tiene que ver con otras dos clasificaciones complementarias: la "ecológica", que distingue los grupos sociales en función de la cercanía o lejanía de los grandes ríos (tewokw-lheley, "habitantes del río", y tahnyi-lheley, "habitantes del bosque"), y la "topológica", basada en los puntos cardinales (phäm-lheley, "habitantes del río arriba", y chäm-lheley, "habitantes del río abajo"). Auténticas coordenadas sociológicas de la identidad, esos principios resultan fundamentales para entender un ordenamiento 
del espacio y del tiempo al cual los wichís están particularmente atentos. A su vez, retomando la expresión de Stephen Kidd, Montani discute la idea de los wichís como sociedad "minimalista", el rechazo consciente de la especialización laboral o técnica, la vigencia de la reciprocidad restringida o del principio rector de la voluntad (lëhusek) en todos sus registros: como voluntad vital, como buena voluntad y como fuerza de voluntad (Palmer).

Podría decirse que los siguientes capítulos contienen el núcleo de la obra. Montani parte de los conceptos nativos de "morada" y de "aldea" para luego llegar a la "casa" (capítulo cuarto) y asimismo a todos los objetos contenidos en ella (capítulo quinto). Retoma de José Braunstein la metáfora de la geometría fractal: la sociedad wichí parece dotada de una suerte de homotecia interna que repite las mismas figuras a distinta escala -así, por ejemplo, el grupo doméstico es como una planta de cháguar y "crece hasta que de ella salen estolones, que en la medida que arraigan dan lugar a nuevas plantas i.e. nuevos grupos domésticos" (p. 183). Es precisamente la bromeliácea chitsaj, planta arquetípica en el universo wichí, la que nos proporciona los más sorprendentes paralelos lingüísticos (aunque se me ocurre otra imagen, seguramente menos complicada: la matrioshka rusa). La wichí es pues una sociedad que "contiene" y se reproduce a sí misma en diversos niveles de la realidad por medio de representaciones análogas, traducibles entre sí. Pero a la vez no admite demasiadas "licencias", sobre todo de tipo emotivo. La contención ascética de las emociones resulta preventiva, pero a la vez protectora: en esta clave parece evidente que los misioneros anglicanos que trabajaron con los wichí fueron hábiles al servirse de una noción de censura que los indígenas conocían bien.

10 En el análisis de la "morada", el lexema wet se presenta como hilo conductor que nos indica todo aquello que la categoría abarca y físicamente contiene: así, tenemos la morada del agua (inät-wet), la morada del juego (lëkoy-wet), la morada del danzar (lëkatinaj-wet), la morada de la buena voluntad o iglesia (nohusewet), la morada de la enseñanza (nochujwehnyaj-wet), la morada de los cadáveres o cementerio (lëpitsehnyëywet) y finalmente la casa (lëwet), que a su vez comprende a los grupos domésticos y residenciales (nowet-lheley), cuya composición Montani aclara apoyándose en los mitos, genealogías, imágenes y relatos -al fin y al cabo, se trata de la "gente de la casa de alguien" (p. 182). La "morada", de esta forma, ofrece un criterio ordenador de la realidad que contiene y a la vez determina tareas y roles bien tangibles. La casa es por ejemplo un ámbito que contiene instrumentos, recipientes, artefactos, pero a la vez rige con orden flexiblemente geométrico la praxis de todos aquellos que buscan utilizarlos. Hecha a imagen y semejanza de la mujer, la casa es como un útero: pertenece al universo femenino porque el principio de la uxorilocalidad emparienta a las mujeres a través de las generaciones, transformándolas en el centro del espacio protegido en un sentido tanto físico como estructural. Pero el criterio que utiliza Montani para describir "las cosas en la casa" es ante todo lingüístico: el fogón, los recipientes, los instrumentos. Los recipientes se componen con el lexema hi ("recipiente") o bien mediante el sufijo -thi. Si va acompañado por el marcador de tercera persona (lëhi), el primero posee el significado de "útero", y el sufijo sirve para derivar un verbo a un sustantivo que signifique "el recipiente donde se desarrolla la acción expresada por el verbo" (p. 231). La acción, de nuevo, aparece contenida y protegida por su recipiente.

11 El sexto capítulo retoma y profundiza los temas introducidos en la primera parte. El círculo se cierra en la medida en que, a esta altura de la exposición, el lector posee ya una imagen de la sociedad wichí en todas sus dimensiones, basada tanto en las descripciones 
bibliográficas como en la propia investigación etnográfica. Ambas descripciones no desentonan sino que se complementan, enlazándose con gusto, rigor y una sencillez balsámica. Particularmente destacables, en este sentido, resultan las páginas del séptimo capítulo dedicadas a las tallas y la pictografía. Las ideas son sugerentes: ¿qué significa esculpir? La secuencia es compleja pero vale la pena seguirla: el escultor "mira" (iyahïn) y "estudia" (itetsan) con atención, "su voluntad recuerda lo que miró" (lëhusek itichunëy mak të iyahïnte) y sólo así puede luego "reproducirlo" o "copiar" (itenlä).

12 Más allá del tecnicismo, las preguntas que plantea Montani son de largo aliento. De hecho, tras haber analizado el estilo abstracto y geométrico de los dibujos reproducidos por las mujeres en las bolsas y, por otra parte, el estilo más realista-naturalista que los hombres emplean en sus tallas, procura desentrañar su significado más íntimo: "Las bolsas enlazadas son en cierto nivel metáforas sólidas proyectadas por la mujer hacia los hombres, sus otros intergrupales" (p. 473). A través de la creación y "procreación" de estos artefactos las mujeres trascienden la alteridad de su género domesticando tanto a su alter ego masculino como a aquel "otro" del universo animal, al mismo tiempo que consiguen volver mucho más familiar -tal como enseña el mito chaqueño- su origen estelar. En este sentido, no parece que su papel en la sociedad contemporánea haya cambiado demasiado. A pesar de que los artefactos femeninos encuentran espacios de circulación más allá del propio grupo y sufren pequeñas variaciones formales a nivel de los significantes, el significado no ha mutado. Las bolsas siguen siendo la representación material de todo cuanto las mujeres "son" y "hacen". En contrapartida, las tallas, no tan culturalmente presentes como productos arquetípicos del universo del hombre, son sin embargo preciosas metáforas de la masculinidad. Montani reconstruye su origen a través del análisis comparativo de una serie de objetos propiamente wichí (morteros, fuentes, cucharas) estudiados por Erland Nordenskiöld, del cotejo con otros artefactos caduveos (peines tallados en asta) recogidos por el viajero-etnógrafo italiano Guido Boggiani, y de una serie no menos importante de objetos enxet (animalitos de cera) reportados por el misionero anglicano Barbrooke Grubb. Los hombres wichí esculpen animales que quieren y aprecian, cuya postura caracteriza el habitus tradicional del ethos masculino: la serenidad, la espera parsimoniosa, la sorpresa temerosa. De esta forma las tallas se convierten en una representación cabal de la masculinidad wichí, aunque dirigidas a una alteridad que ya no es la femenina en el seno del endogrupo. Resulta interesante reflexionar sobre qué y cómo los hombres wichí han decidido compartir, mostrar y extraer de su circuito socioeconómico. Retomando la imagen saussuriana, me pregunto si en esos artefactos -sublimaciones bellas y brillantes de la virilidad masculina- el significado va de la mano con el significante; sospecho que la respuesta tal vez suponga un análisis de las nuevas formas de pintura wichí, en particular las femeninas, tema apenas explorado en el texto pero no por ello menos atractivo. Mientras tanto, "hasta donde sé", este nuevo libro de Rodrigo Montani plantea esta y otras cuestiones regalándonos una de las etnografías wichís más completas, rigurosas y actualizadas que existen. 


\section{AUTORES}

\section{ZELDA ALICE FRANCESCHI}

Università di Bologna 